\title{
A three-dimensional solution of hydraulic fracture width for wellbore strengthening applications
}

\author{
Jincai Zhang ${ }^{1,2} \cdot$ Shangxian Yin ${ }^{2}$
}

Received: 22 August 2018 / Published online: 3 May 2019

(c) The Author(s) 2019

\begin{abstract}
Determining the width of an induced hydraulic fracture is the first step for applying wellbore strengthening and hydraulic fracturing techniques. However, current 2-D analytical solutions obtained from the plane strain assumption may have large uncertainties when the fracture height is small. To solve this problem, a 3-D finite element method (FEM) is used to model wellbore strengthening and calculate the fracture width. Comparisons show that the 2-D plane strain solution is the asymptote of the 3-D FEM solution. Therefore, the 2-D solution may overestimate the fracture width. This indicates that the 2-D solution may not be applicable in 3-D conditions. Based on the FEM modeling, a new 3-D semi-analytical solution for determining the fracture width is proposed, which accounts for the effects of 3-D fracture dimensions, stress anisotropy and borehole inclination. Compared to the 2-D solution, this new 3-D semi-analytical solution predicts a smaller fracture width. This implies that the 2-D-based old design for wellbore strengthening may overestimate the fracture width, which can be reduced using the proposed 3-D solution. It also allows an easy way to calculate the fracture width in complex geometrical and geological conditions. This solution has been verified against 3-D finite element calculations for field applications.
\end{abstract}

Keywords Hydraulic fracture $\cdot$ Fracture width $\cdot$ Wellbore strengthening $\cdot$ Fracture propagation $\cdot 3-D$ modeling

\section{Introduction}

Drilling operations encounter many challenges when the mud weight windows are narrow. For example, severe mud losses or lost circulation is one of the major challenges for drilling in a depleted reservoir because of its low fracture gradient. Therefore, wellbore strengthening is required for increasing the fracture gradient of the rock, widening the mud weight window and consequently enhancing the well integrity and mitigating mud losses. Wellbore strengthening techniques have been successfully used to increase formation fracture gradient, reduce mud losses and access resources that may have been undrillable using conventional drilling

Edited by Yan-Hua Sun

Jincai Zhang

zhangjincai@yahoo.com

$\triangle$ Shangxian Yin yinshx03@126.com

1 Sinopec Tech Houston, Houston, USA

2 North China Institute of Science and Technology, Yanjiao 065201, Hebei, China methods (Alberty and McLean 2004; van Oort et al. 2009; Zhang et al. 2016).

Numerical modeling indicates that after creating a bi-wing fracture in a wellbore, the tangential stress increases markedly around the fracture and the wellbore (Fig. 1). When the fracture is plugged, the wellbore is strengthened which makes it difficult to create new fractures around the wellbore. Laboratory experiments verified that wellbore strengthening can greatly increase the fracture gradient. For instance, laboratory experiments in Roubidoux sandstone cores show that the formation breakdown pressures were increased by $39 \%-65 \%$ and fracture initiation pressures were increased by $15 \%-36 \%$ when oil-based mud with nanoparticles combined with graphite was used to seal the fractures (Contreras et al. 2014). Methods for wellbore strengthening and enhancing fracture gradients have been proposed, and great outcomes have been achieved in drilling to reduce drilling risks of mud losses (van Oort et al. 2009; Zhang and Yin 2017). The drilling industry converges mainly on two wellbore strengthening methods: i.e., the stress cage method (Alberty and McLean 2004) and tip resistance by the development of an immobile mass (Dupriest 2005). Dupriest (2005) pointed out that regardless of the type of treatment used, integrity is increased by widening the fracture to 


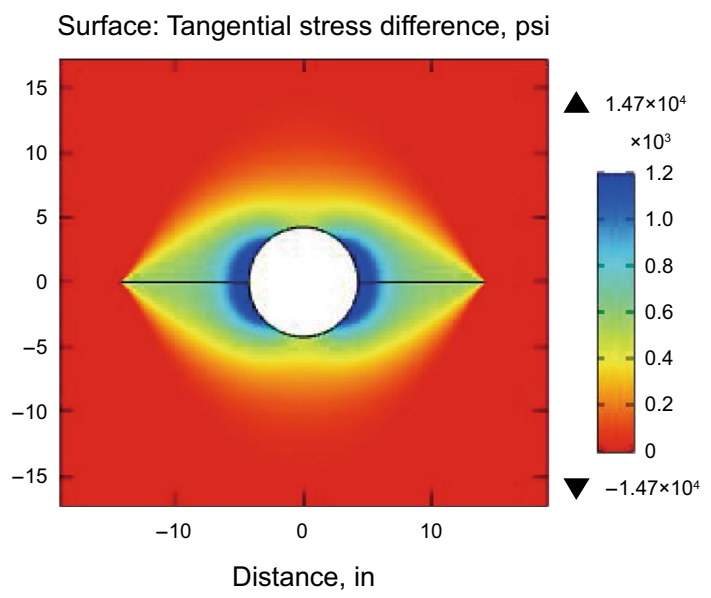

Fig. 1 Increased area of the tangential stress induced by creating a bi-wing fracture in a wellbore modeled by the finite element method (modeling parameters can be found in Table 1)

increase its closing stress. The stress cage wellbore strengthening method has been applied to several hundred wells (Aston et al. 2004, 2007), making those conventionally undrillable wells (because of their narrow drilling margins) able to be drilled successfully. For a successful wellbore strengthening application, the fracture width is one of the most important parameters, because the particle concentration required for plugging the fracture in wellbore strengthening is dependent strongly on the fracture width as laboratory experiments have verified (Guo et al. 2014).

The methods for the fracture width calculations are summarized in this paper. Then, a 3-D finite element method (FEM), Comsol Multiphysics software, is used to model wellbore strengthening and calculate the fracture width. A comparison of 3-D FEM results and the 2-D plane strain solution shows that the 2-D model may overestimate the fracture width. Therefore, a 3-D solution for the fracture width is needed, which is the motivation for this paper.

\section{2-D solutions of the fracture widths near the wellbores}

\subsection{Existing analytical solutions for the fracture widths}

The 2-D plane strain solution of the fracture width for a circular crack was first proposed by Sneddon and Elliott (1946) in the following equation:

$w(x)=\frac{4\left(1-v^{2}\right)}{E} p_{0} \sqrt{L^{2}-x^{2}}$

where $w(x)$ is the fracture width or aperture at a distance $x$ from the center of the crack; $E$ is Young's modulus; $\nu$ is

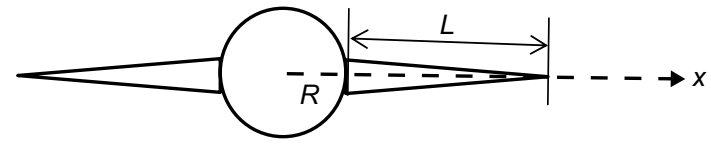

Fig. 2 Wellbore and fracture growth model

Poisson's ratio; $p_{0}$ is the internal pressure in the crack; $L$ is the fracture half-length or the length in one side of the fracture; and $x$ is the distance from the crack center.

Perkins and Kern (1961) and Geertsma and de Klerk (1969) applied Sneddon and Elliott's solution to the oil and gas industry for hydraulic fracturing applications. They treated the borehole as a circular crack with an internal pressure inside the borehole and an isotropic far-field horizontal stress exerted to the wellbore. Alberty and McLean (2004) proposed a 2-D solution to determine the fracture width in the stress cage method for wellbore strengthening based on the solution of Sneddon and Elliott (1946). They assumed that the borehole is a circular crack. Using the linear model of fracture propagation (Sneddon and Elliott 1946; Geertsma and de Klerk 1969), the closed-form solution of the fracture width in the plane strain condition for a vertical well is written in the following equation (Alberty and McLean 2004):

$w(x)=\frac{4\left(1-v^{2}\right)}{E}\left(p_{\mathrm{w}}-S_{\mathrm{h}}\right) \sqrt{(L+R)^{2}-x^{2}}$

where $p_{\mathrm{w}}$ is the internal mud pressure in the wellbore; $S_{\mathrm{h}}$ is the horizontal stress with assumption of two equal horizontal stresses; and $R$ is the wellbore radius (Fig. 2).

This model is limited to a vertical borehole with two equal horizontal stresses. As the difference between the minimum and maximum horizontal stresses increases, the aperture of the fracture becomes larger than that predicted by Eq. 2 .

\subsection{Semi-analytical solution accounting for stress anisotropy}

Many of the wells being drilled are deviated, and the three far-field stresses are very different. In this case, the analytical solution offered by Alberty and McLean (2004) in Eq. (2) would underestimate the fracture width due to the stress anisotropy resulting from the borehole deviation. Therefore, a new method is needed to handle stress anisotropy for calculating the fracture width. Some research has been conducted considering the stress anisotropy (Guo et al. 2011; Marita and Fuh 2012; Shahri et al. 2015; Mehrabian and Jamison 2015; Zhong et al. 2017). However, there is no commonly used analytical method to handle the stress anisotropy; therefore, a numerical method is required to model the fracture width. The numerical solution is normally performed using complex 


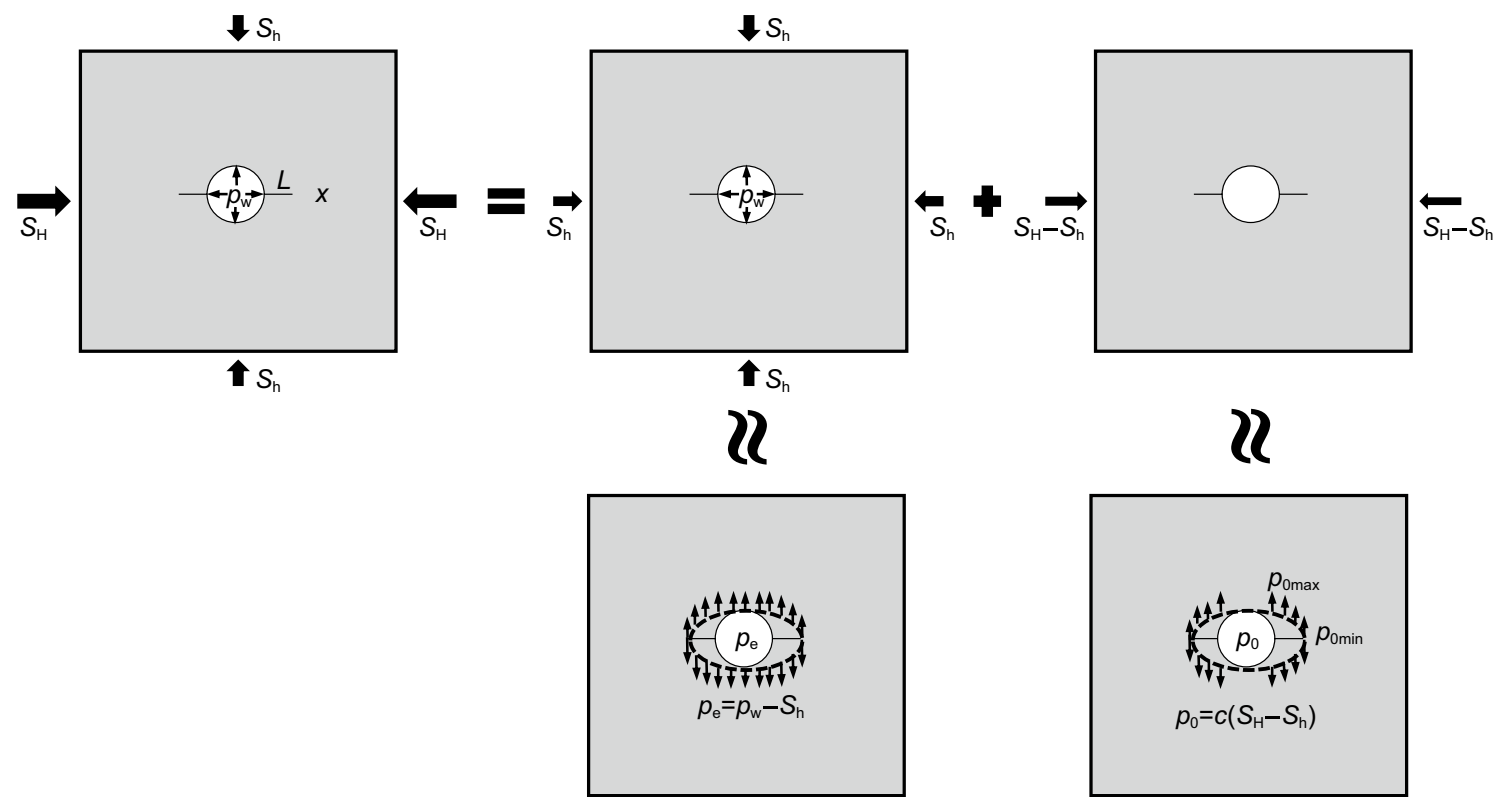

Fig. 3 Schematic wellbore and fracture model under anisotropic far-field stresses, which can be superposed by two separate models

commercial software, which requires special training, licensing for each potential user and the manual transfer of data from company databases to the commercial FEM software. This requires specialists to conduct the analysis and increases costs due to software licensing, as well as the potential for human-generated errors in manually moving data between the different programs. An analytical solution for the presence of stress anisotropy would be a practical solution to address these issues. Applying the superposition principle (Fig. 3), a new 2-D semi-analytical solution for the fracture width in a vertical borehole accounting for in situ stress anisotropy was proposed (Zhang et al. 2016) in the following equation:

$w(x)=\frac{4\left(1-v^{2}\right)}{E}\left[p_{\mathrm{w}}-S_{\mathrm{h}}+c\left(S_{\mathrm{H}}-S_{\mathrm{h}}\right)\right] \sqrt{(L+R)^{2}-x^{2}}$

where $E$ is Young's modulus of the rock (for practical applications, the dynamic modulus is suggested to be used) and $c$ is the stress anisotropy factor.

The derivation of Eq. 3 can be found in the appendix in Zhang et al. (2016). In the derivation, the stress anisotropy factor $(c)$ was considered to account for the impact of the horizontal stress difference. It was obtained from the FEM numerical modeling based on more than a hundred case applications. The stress anisotropy factor can be expressed in the following form, if the length and radius are expressed in inches:

$c=\frac{0.368 R^{1 / 2}}{[L+3(x-R)]^{1 / 1.3}}$

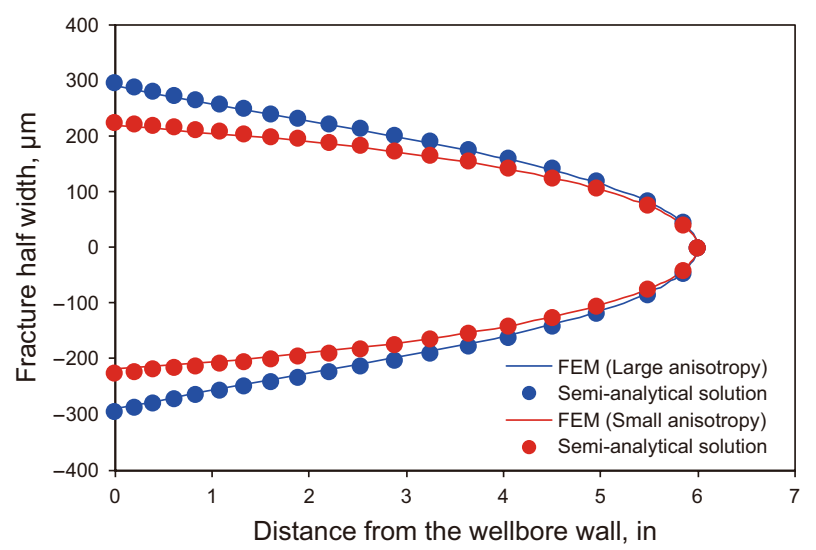

Fig. 4 Comparisons of the semi-analytical solution calculated from Eqs. 3 and 4 and the 2-D FEM solution in small and large horizontal stress anisotropies

where the units of $R, L$ and $x$ are in inches. Although $c$ has a unit, when the units are consistent, it is a constant; therefore, $c$ is an empirical parameter.

In metric unit, if the length and radius are expressed in meters, $c$ can be rewritten in the following form:

$c=\frac{0.137 R^{1 / 2}}{[L+3(x-R)]^{1 / 1.3}}$

where the units of $R, L$ and $x$ are in meters.

Figure 4 displays the fracture shapes calculated from the semi-analytical solution and from the 2-D FEM numerical model for a small anisotropy case $\left(S_{\mathrm{H}}-S_{\mathrm{h}}=100 \mathrm{psi}\right)$ and a 
Table 1 In situ stresses and rock properties used in the FEM analysis

\begin{tabular}{lllllll}
\hline $\begin{array}{l}\text { Minimum horizon- } \\
\text { tal stress } S_{\mathrm{h}}, \mathrm{psi}\end{array}$ & $\begin{array}{l}\text { Maximum hori- } \\
\text { zontal stress } S_{\mathrm{H}}, \\
\mathrm{psi}\end{array}$ & $\begin{array}{l}\text { Vertical stress } \\
S_{\mathrm{V}}, \mathrm{psi}\end{array}$ & $\begin{array}{l}\text { Downhole mud } \\
\text { pressure } p_{\mathrm{w}}, \mathrm{psi}\end{array}$ & $\begin{array}{l}\text { Young's modulus } \\
\text { of the rock } E, \\
\text { Mpsi }\end{array}$ & $\begin{array}{l}\text { Poisson's ratio of } \\
\text { the rock } v\end{array}$ & $\begin{array}{l}\text { Hole diameter } d \text {, in } \\
5953\end{array}$ \\
\hline 6953 & 7863 & 6480 & 1.09 & 0.225 & 8.5 \\
\hline
\end{tabular}

large anisotropy case $\left(S_{\mathrm{H}}-S_{\mathrm{h}}=1000 \mathrm{psi}\right)$. The in situ stresses and rock properties used in the analysis are listed in Table 1 with varied $S_{\mathrm{H}}$, i.e., $S_{\mathrm{H}}=6053$ psi in the small anisotropy case and $S_{\mathrm{H}}=6953$ psi in the large anisotropy case. Figure 4 shows that the results in the two solutions match very well.

In a wellbore cross section orthogonal to the borehole axis in an inclined borehole, the maximum and minimum far-field principal stresses $\left(S_{\max }, S_{\min }\right)$ in the cross section can be calculated from the in situ stresses $\left(S_{\mathrm{h}}, S_{\mathrm{H}}, S_{\mathrm{V}}\right)$. Inserting $S_{\max }$ and $S_{\min }$ into Eq. 3, the fracture width can be obtained for the inclined borehole. In this case, Eq. 3 becomes:

$w(x)=\frac{4\left(1-v^{2}\right)}{E}\left[p_{\mathrm{w}}-S_{\min }+c\left(S_{\max }-S_{\min }\right)\right] \sqrt{(L+R)^{2}-x^{2}}$

where $S_{\max }$ and $S_{\min }$ are the maximum and minimum farfield stresses in the wellbore cross section perpendicular to the borehole axis. In an inclined borehole, $S_{\max }$ and $S_{\min }$ can be estimated using the following equations (Zhang 2013):

$$
\begin{aligned}
\sigma_{x}^{0} & =\left(S_{\mathrm{H}} \cos ^{2} \alpha+S_{\mathrm{h}} \sin ^{2} \alpha\right) \cos ^{2} i+S_{\mathrm{V}} \sin ^{2} i \\
\sigma_{y}^{0} & =S_{\mathrm{H}} \sin ^{2} \alpha+S_{\mathrm{h}} \cos ^{2} \alpha \\
S_{\max } & =\max \left(\sigma_{x}^{0}, \sigma_{y}^{0}\right) \\
S_{\min } & =\min \left(\sigma_{x}^{0}, \sigma_{y}^{0}\right)
\end{aligned}
$$

where $i$ is the borehole inclination relative to the vertical direction; $\alpha$ is the borehole azimuth relative to the maximum horizontal stress direction; $S_{\mathrm{V}}$ is the overburden stress; and $\sigma_{x}^{0}, \sigma_{y}^{0}$ are the intermediate stress values exerted on the wellbore cross section in the $x$ - and $y$-directions, respectively.

\subsection{Limitations of the 2-D plane strain solution}

The 2-D semi-analytical solution (Eq. 3) has been applied for wellbore strengthening in several drilling projects in the Gulf of Mexico and the North Sea. In the 2-D plane strain solution, the fracture is assumed very long in one direction compared to other directions. This assumption may be appropriate for a long fracture, but it might not be suitable for a near-wellbore fracture or a fracture in its early propagating stage. When a hydraulic fracture is in its early propagation stage, it mainly propagates in the two major principal stress directions (e.g., the vertical and maximum horizontal stress directions for a vertical hydraulic fracture). In this case, a 2-D plane strain solution may not work properly, and a 3-D solution is needed for a better description of nearwellbore fractures.

\section{3-D solution of the fracture width for near-wellbore fractures}

\subsection{3-D FEM modeling of fracture widths}

Numerical methods have been used to model stresses, deformations and stabilities of boreholes caused by drilling (Feng et al. 2015; Feng and Gray 2018; Zhang et al. 2003, 2007). In this study, the FEM is used to model stresses and deformations of near-wellbore hydraulic fractures for wellbore strengthening applications. Prior to the numerical study, we validated this numerical method in 3-D wellbores against Kirsch's analytical solution (Bradley 1979) of wellbore stresses and displacements (Zhang et al. 2016). After the validation, we built a 3-D elliptical fracture for the finite element modeling (Fig. 5a) to examine the stress distribution, fracture deformation and fracture aperture changes in a wellbore. A Gulf of Mexico well from Alberty and McLean (2004) is used in the modeling. But here a higher maximum horizontal stress is assumed to examine in situ stress anisotropy. The in situ stresses and rock properties in the studied well are listed in Table 1. A 3-D model, similar to the PKN elliptical fracture (the PKN is a hydraulic fracturing model developed by Perkins and Kern 1961 and then refined by Nordgren 1972), is studied. The 3-D FEM symmetrical meshes (the symmetrical plane is the bottom plane of Fig. 5b, i.e., the central horizontal plane of Fig. 5a) shown in Fig. 5b are used to simulate a borehole with a PKN-type fracture. Using rock mechanics sign convention, the compressive stress is positive, and the tensile stress is negative in this study.

In the 3-D modeling, we model the fracture width variations with varied fracture heights for each case with a fixed fracture length in order to compare with the 2-D plane strain solution. The purpose of the modeling is to verify whether the 2-D plane strain solution is applicable to the 3 -D conditions. In the 3-D FEM modeling, we use Table 1 as the inputs and Fig. 5 as the fracture model. The fracture 
Fig. 5 a Schematic 3-D PKN elliptical fracture studied in the 3-D FEM modeling. b FEM half-model is symmetrical on the bottom of the $z$-plane (i.e., the central horizontal plane of Fig. 5a) and the maximum horizontal, minimum horizontal and vertical stresses are in the $x$-, $y$ and $z$-directions, respectively

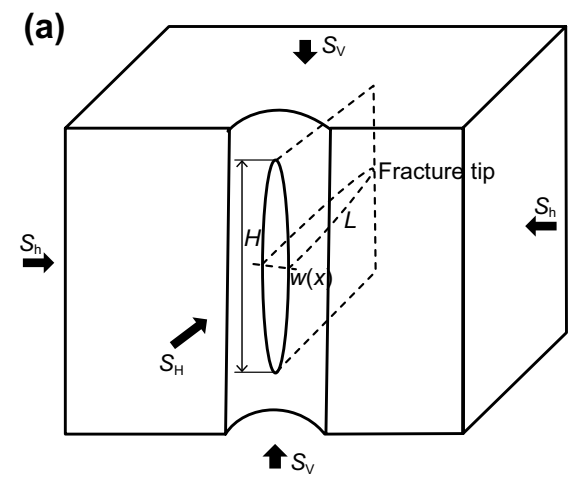

(b)

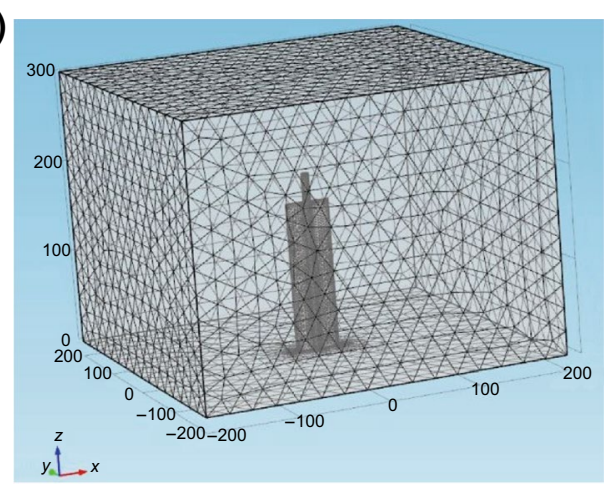

(a)

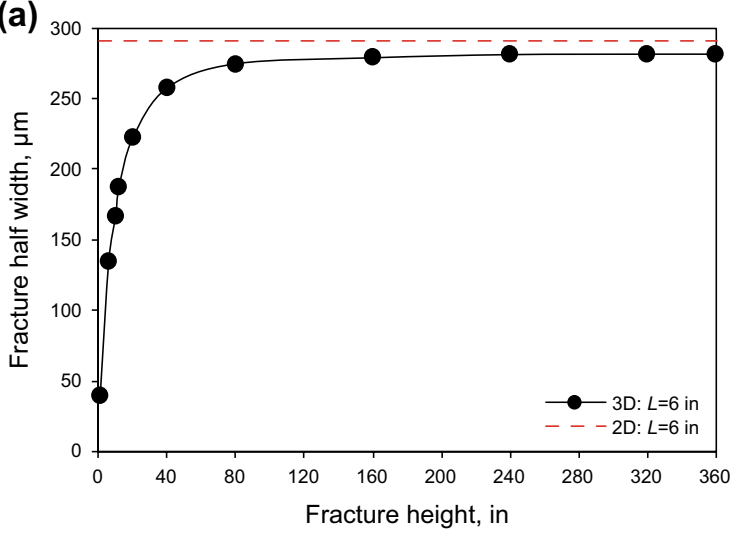

(b)

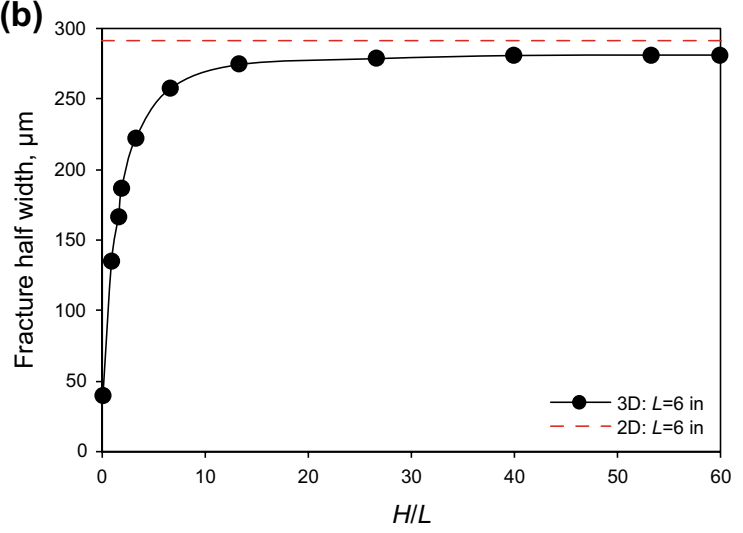

Fig. 6 Fracture width variation obtained from 3-D FEM modeling compared to 2-D plane strain FEM result (fracture length $L=6$ in.). a Fracture half-width versus the fracture height $(H)$. b Fracture half-width versus the ratio of fracture height to fracture length $(H / L)$. Notice that the fracture width and distance from the wellbore wall are plotted in different units for the conventional notation

widths have the maximum values in the central plane of the borehole (i.e., the dashed horizontal plane in Fig. 5a). The following analysis focuses on the fracture behavior in this horizon. Figure 6 shows that the fracture half-width, $w(x) / 2$, increases as the fracture height increases (in this case, fracture length $L=6$ inches). When the fracture height is small $(H<40$ inches or $H / L<6)$, the fracture half-width increases significantly as the fracture height increases. When the fracture height is relatively large $(H>60$ inches in Fig. 6a or $H / L>10$ in Fig. 6b), the fracture width increases slowly and approaches the 2-D plane strain FEM solution (the dashed line in Fig. 6). The same trend is obtained for the cases with large fracture lengths, as shown in Figs. 7 and 8. It demonstrates that the 2-D plane strain FEM solution is the asymptote of the 3-D solution. This implies that the 2-D plane strain solution might not be applicable in 3-D conditions, particularly when the fracture height or $H / L$ is small.

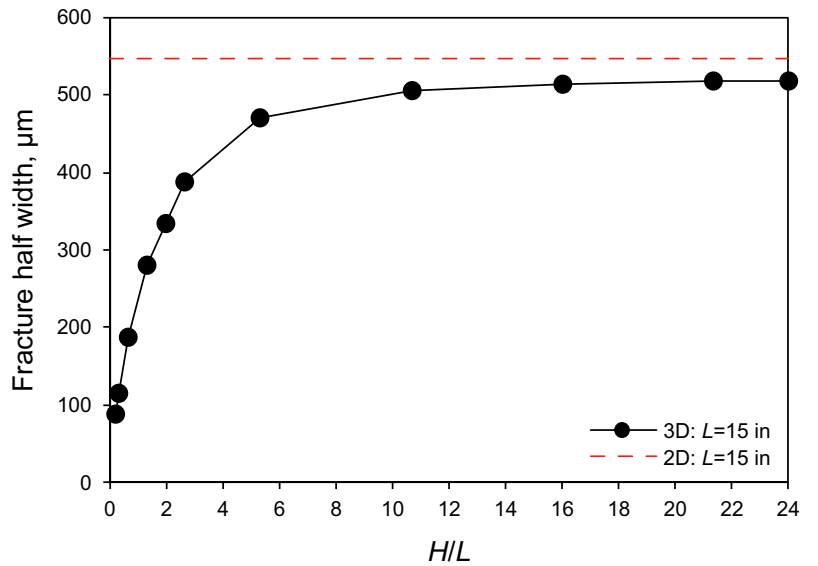

Fig. 7 Fracture width variation versus the ratio of fracture height to fracture length $(H / L)$ from 3-D FEM modeling compared to 2-D plane strain FEM result (fracture length $L=15$ in.) 


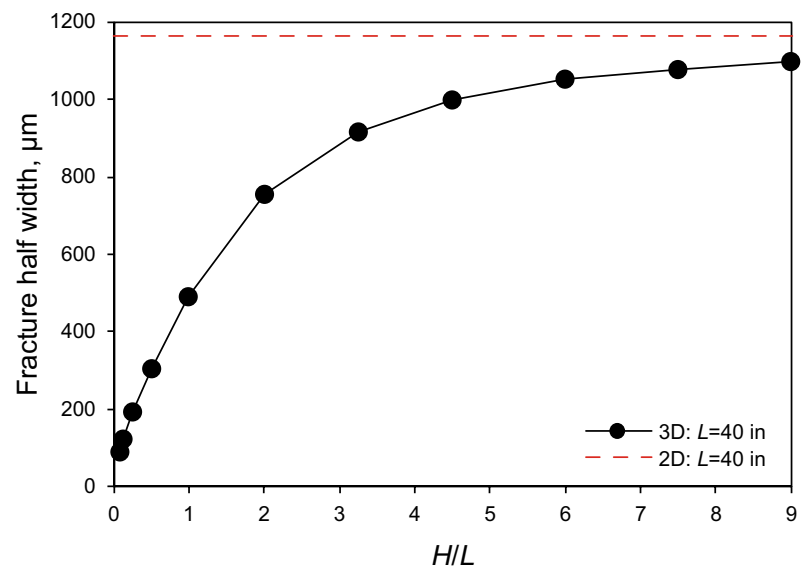

Fig. 8 Fracture width variation versus the ratio of fracture height to fracture length $(H / L)$ from 3-D FEM modeling compared to 2-D plane strain FEM result (fracture length $L=40$ in.)

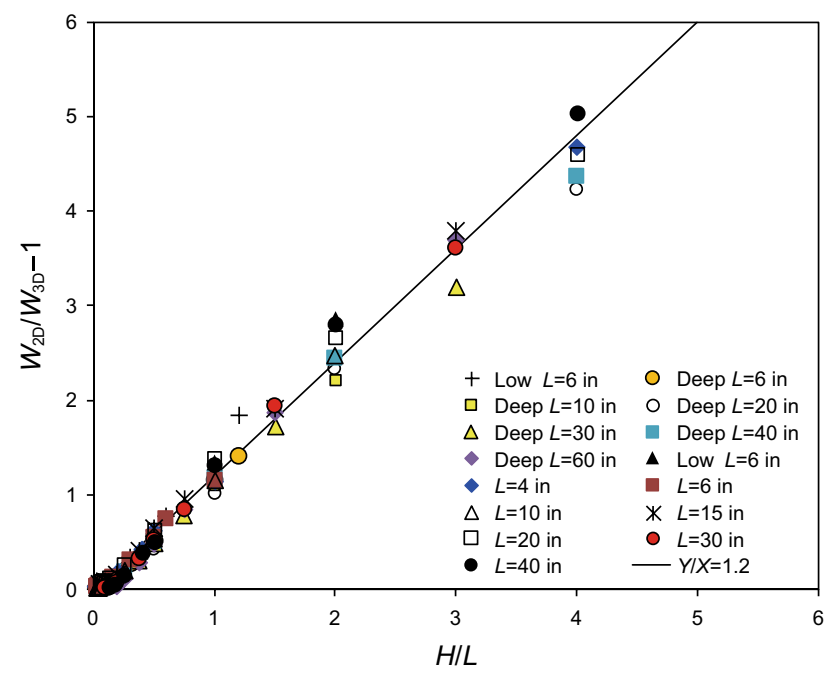

Fig. 9 Fracture widths in 2-D and 3-D FEM solutions related to the ratio of fracture length to fracture height for 15 application cases

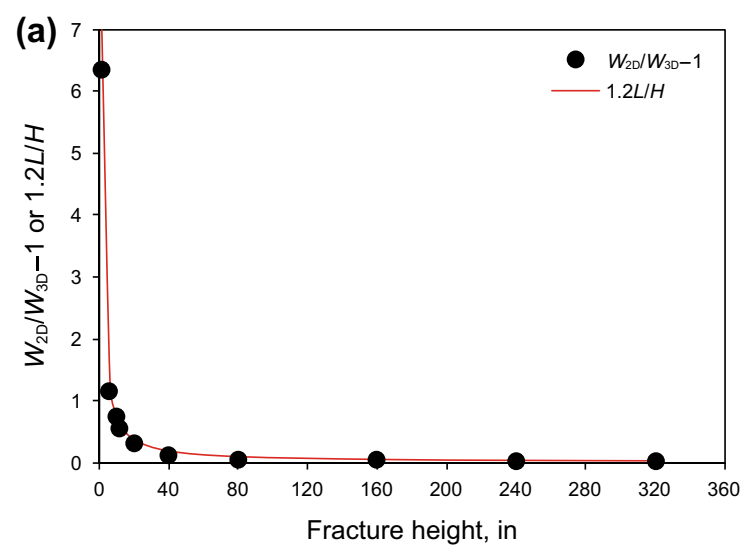

\subsection{3-D semi-analytical solution of the fracture width}

Fifteen application cases of 3-D FEM near-wellbore fractures are modeled, and the fracture widths with different $L / H$ (ratio of fracture length to fracture height) values are calculated in each case. The corresponding 2-D FEM plane strain solution is also obtained for each case. The fracture widths in 2-D and 3-D conditions and $L / H$ in these cases are plotted in Fig. 9. It can be observed that the fracture widths from the 2-D to 3-D solutions are strongly dependent on the ratio of fracture length to fracture height. The following relationship of the 2-D and 3-D solutions is obtained from the FEM modeling results:

$\frac{w_{2 \mathrm{D}}}{w_{3 \mathrm{D}}}=1+\frac{1.2 L}{H}$

where $w_{2 \mathrm{D}}$ and $w_{3 \mathrm{D}}$ are the fracture widths in 2-D and 3-D cases, respectively.

Or,

$w_{3 \mathrm{D}}=\frac{w_{2 \mathrm{D}}}{k}$

where $k=1+\frac{1.2 L}{H}$

Equations 8-10 are obtained from the fracture initial propagation stage; therefore, they are mainly applicable for near-wellbore fractures.

We verify Eq. 8 by calculating the 2-D and 3-D FEM solutions at different fracture length conditions using the same input parameters shown in Table 1. We then plot $w_{2 \mathrm{D}} / w_{3 \mathrm{D}}-1$ and $1.2 \mathrm{~L} / \mathrm{H}$ versus the fracture heights in Fig. 10. It indicates that the FEM results follow the relation of Eq. 8 very well. We also investigate a deep well to examine the 3-D semi-analytical solution. The in situ stresses and rock properties are listed in Table 2. Figure 11 shows the 3-D FEM numerical results compared to the results calculated

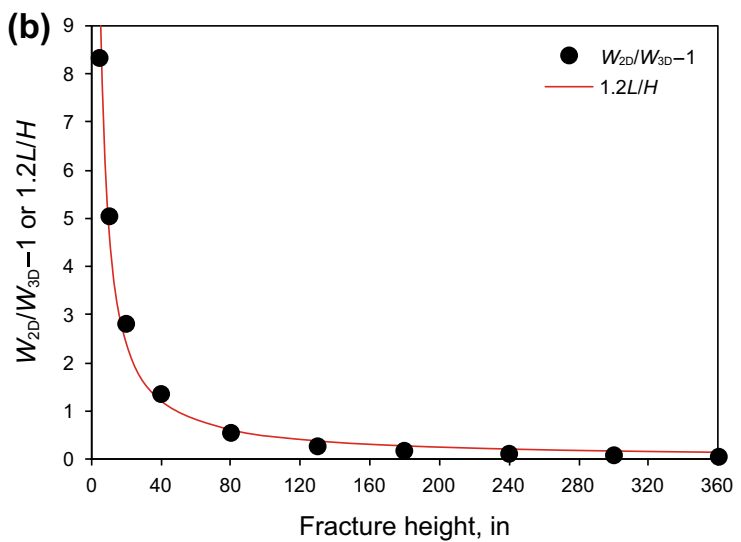

Fig. 10 FEM results in 3-D and 2-D cases versus $L / H$. Left: $L=6$ inches; right: $L=40$ in. 
Table 2 In situ stresses and rock properties used in a deep well

\begin{tabular}{|c|c|c|c|c|c|c|c|}
\hline $\begin{array}{l}\text { Minimum } \\
\text { horizontal stress } \\
S_{\mathrm{h}}, \mathrm{psi}\end{array}$ & $\begin{array}{l}\text { Maximum } \\
\text { horizontal stress } \\
S_{\mathrm{H}} \text {, psi }\end{array}$ & $\begin{array}{l}\text { Vertical stress } \\
S_{\mathrm{V}}, \text { psi }\end{array}$ & $\begin{array}{l}\text { Downhole mud } \\
\text { pressure } p_{\mathrm{w}}, \mathrm{psi}\end{array}$ & $\begin{array}{l}\text { Young's modu- } \\
\text { lus of the rock } E \text {, } \\
\text { Mpsi }\end{array}$ & $\begin{array}{l}\text { Poisson's ratio of } \\
\text { the rock } v\end{array}$ & $\begin{array}{l}\text { Hole diameter } \\
d \text {, in }\end{array}$ & Depth $D, \mathrm{ft}$ \\
\hline 18,260 & 18,680 & 21,680 & 19,120 & 3.38 & 0.15 & 6.125 & 25,000 \\
\hline
\end{tabular}

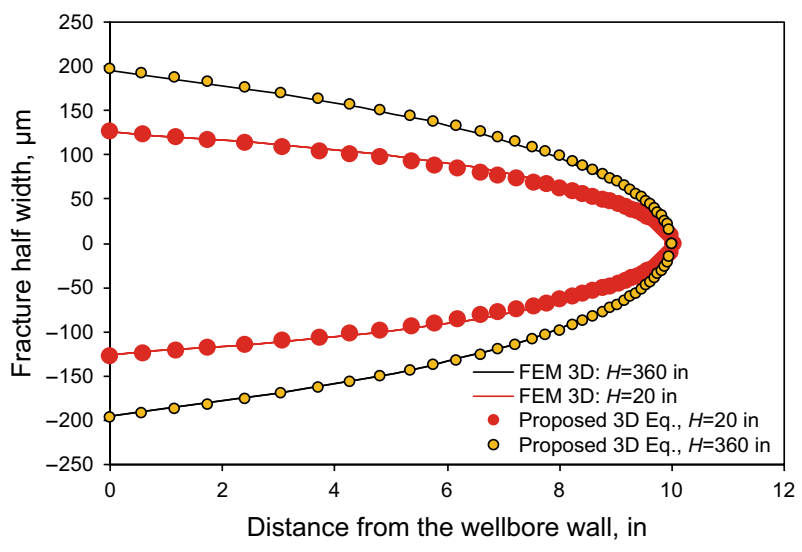

Fig. 11 3-D FEM numerical results compared to the proposed 3-D equation (Eq. 8) for a deep well at a depth of 25,000 ft. The $w_{2 \mathrm{D}}$ in Eq. 8 is obtained from the 2-D semi-analytical solution (Eq. 3)

from the proposed 3-D fracture width (Eq. 8), in which the $w_{2 \mathrm{D}}$ is obtained from the 2-D semi-analytical solution (Eq. 3) for a deep well at a depth of 25,000 ft for $L=10$ inches and $R=6.125$ inches. Again, the match is very good.

It is commonly assumed that a near-wellbore vertical hydraulic fracture propagates uniformly in the vertical and horizontal directions. Therefore, the fracture length $(L)$ and height $(H)$ for the uniform propagation should satisfy the condition of $H=2 L$. Inserting $H=2 L$ into Eq. 10, we obtain $k=1.6$. For a 3 -D radially propagating circular crack or penny-shaped crack, Sneddon's solution (Sneddon 1946) is equivalent to $k=\pi / 2=1.57$, which is similar to $k=1.6$ in the linear fracture. The solution of $w_{2 \mathrm{D}}$ can be obtained from the semi-analytical solution in Eq. 3. Therefore, the 3-D semianalytical solution of the fracture width can be obtained by replacing $w_{2 \mathrm{D}}$ in Eq. 8 by Eq. 3 and inserting $H=2 L$. Hence, the 3-D semi-analytical solution of fracture width can be expressed in the following equation:

$w_{3 \mathrm{D}}(x)=\frac{4\left(1-v^{2}\right)}{1.6 E}\left[p_{w}-S_{\min }+c\left(S_{\max }-S_{\min }\right)\right] \sqrt{(L+R)^{2}-x^{2}}$

where $w_{3 \mathrm{D}}(x)$ is the fracture width and $L$ is the fracture length in one side of the wellbore. Compared to the 2-D solution in Eq. 3, the proposed 3-D solution of Eq. 11 predicts a smaller fracture width.
In fact, fracture propagation is markedly dependent on the principal stress magnitudes exerted in the fracture propagation directions. For a vertical hydraulic fracture, the fracture propagation length and height in the horizontal and vertical directions in an isotropic and homogeneous formation should be proportional to the far-field stress magnitudes in the corresponding directions; i.e., $2 L / H$ is directly proportional to $S_{\mathrm{H}} / S_{\mathrm{V}}$. Therefore, if the fracture propagation is dependent on the principal far-field stress magnitudes, then $k$ value in Eq. 10 for a vertical fracture can be rewritten in the following form:

$k=1+\frac{0.6 S_{H}}{S_{V}}$

Therefore, for a vertical fracture in a vertical well, Eq. 8 can be expressed in the following form (Zhang 2019):

$w_{3 \mathrm{D}}(x)=\frac{4\left(1-v^{2}\right)}{\left(1+0.6 S_{\mathrm{H}} / S_{\mathrm{V}}\right) E}\left[p_{\mathrm{w}}-S_{\mathrm{h}}+c\left(S_{\mathrm{H}}-S_{\mathrm{h}}\right)\right] \sqrt{(L+R)^{2}-x^{2}}$

This 3-D semi-analytical solution allows an easy way to compute the fracture width in complex conditions for wellbore strengthening, but it has some assumptions and conditions for applications. The assumptions used to obtain the solution include:

(1) The studied hydraulic fracture is a near-wellbore vertical fracture in an isotropic and homogeneous elastic rock;

(2) The fracture length is short; normally, the half-length of the fracture is $L<50$ inches.

(3) The 2-D semi-analytical solution is used to derive the 3-D semi-analytical solution, in which the 2-D solution is assumed in the plane strain condition.

\section{Conclusions}

Three-dimensional finite element modeling is applied to model near-wellbore hydraulic fracture behavior and to determine the width of the induced hydraulic fracture. Comparisons demonstrate that the 2-D plane strain solution is the asymptote of the 3-D solution. This implies that the 2-D solution might not be applicable in 3-D conditions, because it overestimates the fracture width when $H / L$ is small. 
Based on 3-D FEM modeling, a 3-D semi-analytical fracture width solution is developed to account for 3-D fracture dimensions, stress anisotropy and borehole inclination. In the solution, fracture propagation behaviors along the vertical and horizontal directions are also considered and are related to the far-field stress anisotropy. This 3-D semi-analytical solution allows an easy way to calculate the fracture width and implement wellbore strengthening in complex conditions. It has been verified against 3-D FEM modeling, and the results show that the 3-D semi-analytical solution and the finite element results agree very well.

Acknowledgements This work was partially supported by National Key R\&D Program of China (2017YFC0804108) during the 13th Five-Year Plan Period, National Science Foundation of China (51774136), Natural Science Foundation of Hebei Province of China (D2017508099) and the Program for Innovative Research Team in the University sponsored by Ministry of Education of China (IRT-17R37). The authors wish to thank COMSOL Inc. to provide the Multiphysics FEM software for conducting this research.

Open Access This article is distributed under the terms of the Creative Commons Attribution 4.0 International License (http://creativeco mmons.org/licenses/by/4.0/), which permits unrestricted use, distribution, and reproduction in any medium, provided you give appropriate credit to the original author(s) and the source, provide a link to the Creative Commons license, and indicate if changes were made.

\section{References}

Alberty M, McLean M. A physical model for stress cages. In: SPE annual technical conference and exhibition, 26-29 September, Houston, Texas; 2004. https://doi.org/10.2118/90493-MS.

Aston M, Alberty M, Duncum S, Bruton J, Friedheim J, Sanders M. A new treatment for wellbore strengthening in shale. In: SPE annual technical conference and exhibition, 11-14 November, Anaheim, California, U.S.A.; 2007. https://doi.org/10.2118/110713-MS.

Aston M, Alberty M, McLean M, de Jong H, Armagost K. Drilling fluids for wellbore strengthening. In: IADC/SPE drilling conference, 2-4 March, Dallas, Texas; 2004. https://doi.org/10.2118/87130 $-\mathrm{MS}$.

Bradley WB. Failure of inclined boreholes. J Energy Res Technol. 1979;101(4):232-9. https://doi.org/10.1115/1.3446925.

Contreras O, Hareland G, Husein M, Nygaard R, Alsaba M. Wellbore strengthening in sandstones by means of nanoparticle-based drilling fluids. In: SPE deepwater drilling and completions conference, 10-11 September, Galveston, Texas, U.S.A.; 2014. https:// doi.org/10.2118/170263-MS.

Dupriest FE. Fracture closure stress (FCS) and lost returns practices. In: SPE/IADC drilling conference, 23-25 February, Amsterdam, Netherlands; 2005. https://doi.org/10.2118/92192-MS.

Feng Y, Arlanoglu C, Podnos E, Becker E, Gray KE. Finite-element studies of hoop-stress enhancement for wellbore strengthening. SPE Drill Complet. 2015;30(1):38-51. https://doi. org/10.2118/168001-PA.
Feng Y, Gray KE. Modeling lost circulation through drillinginduced fractures. SPE J. 2018;23(1):205-23. https://doi. org/10.2118/187945-PA.

Geertsma J, de Klerk F. A rapid method of predicting width and extent of hydraulically induced fractures. J Pet Technol. 1969;21(12):1571-81. https://doi.org/10.2118/2458-PA.

Guo Q, Cook J, Way P, Ji L, Friedheim L. A comprehensive experimental study on wellbore strengthening. In: IADC/SPE drilling conference and exhibition, 4-6 March, Fort Worth, Texas, U.S.A.; 2014. https://doi.org/10.2118/167957-MS.

Guo Q, Feng YZ, Jin ZH. Fracture aperture for wellbore strengthening applications. In: 45th U.S. rock mechanics/geomechanics symposium, 26-29 June, San Francisco, California; 2011.

Marita N, Fuh GF. Parametric analysis of wellbore strengthening methods from basic rock mechanics. SPE Drill Complet. 2012;27(2):315-27. https://doi.org/10.2118/145765-PA.

Mehrabian A, Jamison DE. Teodorescu SG Geomechanics of lostcirculation events and wellbore-strengthening operations. SPE J. 2015;20(6):1305-16. https://doi.org/10.2118/174088-PA.

Nordgren RP. Propagation of a vertical hydraulic fracture. Soc Pet Eng J. 1972;12:306-14.

Perkins TK, Kern LR. Widths of hydraulic fractures. J Pet Technol. 1961;13(9):937-49. https://doi.org/10.2118/89-PA.

Shahri MP, Oar TT, Safari R, Karimi M, Mutlu U. Advanced semianalytical geomechanical model for wellbore-strengthening applications. In: IADC/SPE drilling conference and exhibition, 4-6 March, Fort Worth, Texas, U.S.A. 2015. https://doi. org/10.2118/167976-MS.

Sneddon IN, Elliott HA. The opening of a Griffith crack under internal pressure. Q Appl Math. 1946;4:262-6. https://doi.org/10.1090/ qam/17161.

Sneddon IN. The distribution of stress in the neighbourhood of a crack in an elastic solid. Proc R Soc Lond A. 1946;187:229-60. https:// doi.org/10.1098/rspa.1946.0077.

van Oort E, Friedheim J, Pierce T. Avoiding losses in depleted and weak zones by constantly strengthening wellbores. In: SPE annual technical conference and exhibition, 4-7 October, New Orleans, Louisiana; 2009. https://doi.org/10.2118/125093-MS.

Zhang J. Applied petroleum geomechanics. Houston: Gulf Professional Publishing, Elsevier; 2019 in press.

Zhang J. Borehole stability analysis accounting for anisotropies in drilling to weak bedding planes. Int J Rock Mech Min Sci. 2013;60:160-70. https://doi.org/10.1016/j.ijrmms.2012.12.025.

Zhang J, Yin S. Fracture gradient prediction: an overview and an improved method. Pet Sci. 2017;14(4):720-30. https://doi. org/10.1007/s12182-017-0182-1.

Zhang J, Alberty M, Blangy JP. A semi-analytical solution for estimating the fracture width in wellbore strengthening applications. In: SPE deepwater drilling \& completions conference held in Galveston, TX, U.S.A. 2016. https://doi.org/10.2118/180296-MS.

Zhang J, Bai M, Roegiers J-C. Dual-porosity poroelastic analyses of wellbore stability. Int J Rock Mech Min Sci. 2003;40(4):473-83. https://doi.org/10.1016/S1365-1609(03)00019-4.

Zhang X, Jeffrey RG, Thiercelin M. Deflection and propagation of fluid-driven fractures at frictional bedding interfaces: a numerical investigation. J Struct Geol. 2007;29:396-410. https://doi. org/10.1016/j.jsg.2006.09.013.

Zhong R, Miska S, Yu M. Modeling of near-wellbore fracturing for wellbore strengthening. J Nat Gas Sci Eng. 2017;38:475-84. https ://doi.org/10.1016/j.jngse.2017.01.009. 